\title{
Corrosion Behaviour of TiN/ $\alpha-C$ Superhard Nanocomposite Coatings Prepared by a Reactive DC Magnetron Sputtering Process
}

\section{Harish C. Barshilia*, M. Surya Prakash, Aithu Poojari and K. S. Rajam \\ Surface Engineering Division, National Aerospace Laboratories Post Bag No. 1779, Bangalore - 560017} India

*Corresponding author: H. C. Barshilia, E-mail harish@css.nal.res.in

H. C. Barshilia, M. Surya Prakash, A. Poojari and K. S. Rajam, Trans Inst Met Fin, 2004, 82(4), 000

SUMMARY - Nanocomposite coatings of TiN/ $\alpha$-C were prepared on tool steel substrates using a multitarget reactive DC magnetron sputtering process at various TiN layer thicknesses $(0.6-2.8 \mathrm{~nm})$. The $\alpha-C$ layer thickness was approximately $0.45 \mathrm{~nm}$. Structural characterisation of the coatings was done by X-ray diffraction $(X R D)$. Incorporation of an $\alpha$-C phase in TiN matrix reduced crystallite size of the coatings, as revealed by $X R D$ and atomic force microscopy. XRD data showed that the nanocomposite coatings exhibited $\{111\}$ texture and the average crysta-llite size was ca. 7.5-9.0 $\mathrm{nm}$. Nanoindentation data showed that $1.5 \mathrm{um}$ thick nanocomposite coatings exhibited a maximum hardness of $5100 \mathrm{~kg} \mathrm{~mm}^{-2}$. The potentiodynamic polarisation of $1.5 \mu \mathrm{m}$ thick coatings in $0.5 \mathrm{M} \mathrm{HCl}$ solution indicated that the nanocomposite coatings exhibited superior corrosion protection of the tool steel substrate as compared to the single layer TiN coatings of similar thicknesses. Enhancement in the corrosion behaviour of the nanocomposite coatings has been attributed to small crystallite size and dense microstructure. Potentiodynamic polarisation studies conducted on ca. $100 \mathrm{~nm}$ thick nanocomposite coatings revealed that for a given $\alpha$-C layer thickness the corrosion current decreased with a decrease in TiN layer thickness. This was supported by scanning electron microscopy (SEM) studies on the corroded samples. The SEM micrographs showed that density and diameter of the corrosion pits were smaller for nanocomposite coatings as compared to single layer TiN coatings of similar thicknesses.

Keywords: $\quad \mathrm{TiN} / \alpha-\mathrm{C}$ nanocomposites, superhard coatings, magnetron sputtering, structure, mechanical properties, corrosion behaviour

\section{INTRODUCTION}

Environmental issues regarding the disposal of toxic by-products from the production of electroplated hard coatings have led many to consider other hard coatings deposited by physical vapour deposition (PVD) techniques. The most common of these PVD coatings are TiN and $\mathrm{CrN}$. One of the greatest disadvantages of PVD TiN coatings is the columnar microstructure, which leads to a large number of pores in the coatings ${ }^{1}$. These pores deteriorate the mechanical properties of the coatings. The columnar structure also allows micropores/ pinholes to run through the coating thickness, via which the corrosive media may attack the coating/substrate interface ${ }^{2}$. Although, transition metal nitride coatings prepared by PVD techniques are chemically inert, the presence of a large number of pores and columnar microstructure degrades the corrosion behaviour of the coatings significantly. To improve the corrosion protection of the substrate it is, therefore, important to reduce the porosity of the PVD coatings. In addition to impurities on the substrate surface and the substrate state (roughness, scratches, etc.), a large grain size can also induce porosity in the coating. Smaller grain size of the PVD coatings can be achieved by the judicious control of the deposition parameters (e.g. ion bombardment of the coatings during deposition) $)^{3}$.

The corrosion behaviour of $\mathrm{TiN}^{4,5}$ and $\mathrm{CrN}^{6,7}$ coatings is fairly well documented in the literature and various methods have been suggested to improve corrosion resistance of these coatings. These include increased coating thickness ${ }^{8}$, incorporation of interlayers $\left(\mathrm{Ti}^{9}\right.$, electroless deposition $\mathrm{Ni}^{10,11}$ ), alloying of nitrides (TiAlN ${ }^{12}$, $\mathrm{TiCrN}_{\mathrm{x}}{ }^{13}, \mathrm{TiCN}^{14}$ ), intermediate plasma etching during deposition ${ }^{15}$ and multilayer deposition ${ }^{16,17}$

In the last couple of years, significant attention has been devoted on the formation of superhard (hardness $\geq 4000 \mathrm{~kg} \mathrm{~mm}^{-2}$ ) nanocomposite coatings ${ }^{18-20}$. In general, these coatings consist of two phases - a nanocrystalline phase and an amorphous phase or two nanocrystalline phases. The nanocomposite coatings exhibit superior mechanical properties. In nanocomposite coatings, prepared by the multilayer route, incorporation of amorphous phase (e.g. $\alpha-\mathrm{C})$ in the base material (e.g. TiN) not only reduces the crystallite size but also the micro-porosity of the coatings ${ }^{21}$. This is possible because of re-nucleation associated with successive deposition of sublayers. This reduces the grain size and prevents the columnar growth, both of which lead to dense and homogeneous microstructure of the coating. This, in turn, leads to high hardness of the nanocomposite 
coating and good corrosion protection of the substrate. The corrosion behaviour of nanocomposite coatings has not been reported widely in the literature ${ }^{22}$. In this article, the growth of $\mathrm{TiN} / \alpha-\mathrm{C}$ nanocomposite coatings on tool steel substrates by reactive DC magnetron sputtering process is described and the corrosion behaviour of the coatings in $0.5 \mathrm{M} \mathrm{HCl}$ solution using a potentiodynamic polarisation technique is discussed.

\section{EXPERIMENTAL}

Coating deposition and characterisation

The substrate $\left(20 \times 20 \times 2 \mathrm{~mm}^{3}\right)$ used was an M3 tool steel consisting of $1.22 \mathrm{~V}-$ $4.05 \mathrm{Cr}-0.35 \mathrm{Mn}-83.15 \mathrm{Fe}-8.37 \mathrm{Co}-2.86 \mathrm{~W}$ (wt- $\%)$. The substrates were metallographically polished with a final surface roughness of the order of $4-5 \mathrm{~nm}$. The substrates were cleaned in ultrasonic bath for $15 \mathrm{~min}$ roethylene. Further cleaning was done by in situ $\mathrm{Ar}^{+}$ion bombardment, wherein a DC

1 bias of $-850 \mathrm{~V}$ was applied to the substrate for $30 \mathrm{~min}$ prior to the film deposition. The plasma cleaning of the substrate was done at an argon pressure of $0.5 \mathrm{~Pa}$.

Single layer $\mathrm{TiN}, \alpha-\mathrm{C}$ and $\mathrm{TiN} / \alpha-\mathrm{C}$ nanocomposite coatings were deposited using a multi-target reactive DC magnetron sputtering system. This has been described in detail elsewhere ${ }^{23}$, but a schematic diagram of the sputtering system is shown in Figure 1. The sputtering system consists of four sputtering guns (US Thin Film Products, Inc.). Only two sputtering guns were used in the present work. The sputtering guns were shielded from each other so that no overlap of the two particle beams occurred. The vacuum chamber was evacuated using a turbomolecular pump (TMP) backed by a rotary pump. The subwith an in-built substrate heater. The substrate to target distance was $0.054 \mathrm{~m}$. In order to produce varying thicknesses of TiN and $\alpha$-C layers, $75 \mathrm{~mm}$ dia., $6 \mathrm{~mm}$ thick high purity $\mathrm{Ti}(99.95 \%)$ and graphite

Table I. Parameters for the deposition of TiN/ $\alpha$-C nanocomposite coatings

\begin{tabular}{|c|c|c|}
\hline Step & Process & Parameters \\
\hline 1 & In situ substrate cleaning & $\begin{array}{l}\text { Voltage }=-850 \mathrm{~V}, \mathrm{Ar}=17 \mathrm{~cm}^{3} \mathrm{~s}^{-1}, \text { pressure }=0.5 \mathrm{~Pa}, \\
\text { temperature }=300^{\circ} \mathrm{C} \text {, duration }=30 \mathrm{~min}\end{array}$ \\
\hline 2 & Targets cleaning & $\begin{array}{l}\text { (a) Ti: Power }=250 \mathrm{~W} \text {, duration }=20 \mathrm{~min} \\
\text { (b) Graphite: } \text { Power }=245 \mathrm{~W} \text {, duration }=20 \mathrm{~min}\end{array}$ \\
\hline 3 & Ti interlayer & $\begin{array}{l}\text { Power }=250 \mathrm{~W} \text {, bias }=-200 \mathrm{~V}, \mathrm{Ar}=17 \mathrm{~cm}^{3} \mathrm{~s}^{-1} \\
\text { pressure }=0.5 \mathrm{~Pa} \text {, temperature }=300^{\circ} \mathrm{C}, \\
\text { deposition time }=30 \text { min, thickness }=0.5 \mu \mathrm{m}\end{array}$ \\
\hline 4 & Nanocomposite deposition & $\begin{array}{l}\text { Ultimate vacuum }=0.0005 \mathrm{~Pa} \\
\text { Working pressure }=0.36 \mathrm{~Pa} \\
\text { Nitrogen flow rate }=0.8 \mathrm{~cm}^{3} \mathrm{~s}^{-1}, \text { Argon flow rate }=17 \mathrm{~cm}^{3} \mathrm{~s}^{-1} \\
\text { Substrate bias }=-275 \mathrm{~V} \\
\text { Growth rate for TiN }=0.2 \mathrm{~nm} \mathrm{~s}^{-1} \\
\text { Growth rate for } \alpha-C=0.15 \mathrm{~nm} \mathrm{~s}^{-1} \\
\text { Substrate temperature }=300^{\circ} \mathrm{C} \\
\text { Total thickness of the coating }=1.5 \mathrm{um}\end{array}$ \\
\hline 5 & Cooling down and venting & $45 \mathrm{~min}$ \\
\hline
\end{tabular}
each in acetone, ethyl alcohol and trichlostrates were placed on a rotating holder

$(99.99 \%)$ targets were sputtered for different durations in high purity $\operatorname{Ar}(99.999 \%)$ and $\mathrm{N}_{2}(99.999 \%)$ plasma. Typically, TiN/ $\alpha-\mathrm{C}$ nanocomposite coatings were deposited under a base pressure of $0.00005 \mathrm{~Pa}$ and a total $\mathrm{Ar}+\mathrm{N}_{2}$ gas pressure of $0.1 \mathrm{~Pa}$. The flow rates of $\mathrm{N}_{2}\left(0.8 \mathrm{~cm}^{3} \mathrm{~s}^{-1}\right)$ and $\operatorname{Ar}\left(17 \mathrm{~cm}^{3} \mathrm{~s}^{-1}\right)$ were controlled separately by mass flow controllers. During deposition, a de bias of $-275 \mathrm{~V}$ was applied to the substrate to achieve dense microstructure. The coatings were deposited at a substrate temperature of $300^{\circ} \mathrm{C}$. For all the experiments, the sputtering powers were 250 and $245 \mathrm{~W}$ for $\mathrm{Ti}$ and graphite targets, respectively. Under these conditions the growth rates were approximately 0.2 and $0.15 \mathrm{~nm} \mathrm{~s}^{-1}$ for TiN and $\alpha-C$, respectively. The thicknesses of the coatings were calculated by weight gain measurements and verified using cross-sectional scanning electron microscopy (SEM). Reproducible nanocomposite coatings were obtained by a computer operated substrate rotation assembly, which controlled dwell time of the substrate underneath each target very precisely. The total coating thickness was $1.5 \mu \mathrm{m}$. Nanocomposite coatings were deposited at various TiN layer thicknesses $(0.6-2.8 \mathrm{~nm})$. A Ti interlayer, $c a .0 .5 \mu \mathrm{m}$ thick, was also incorporated between the substrate and the films for improved

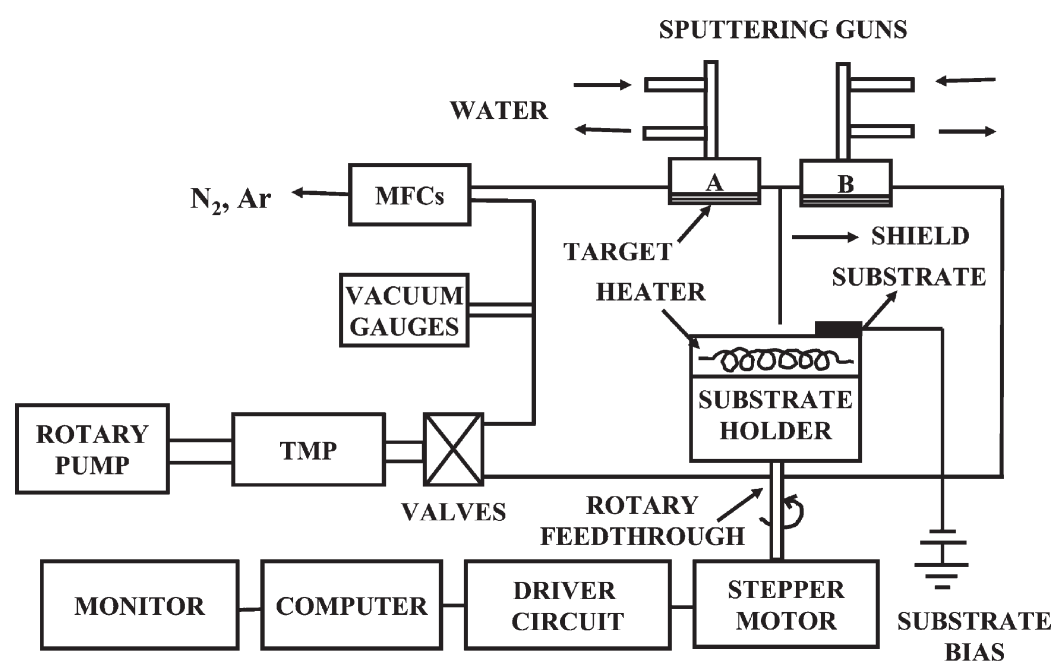

Figure 1. Schematic diagram of the reactive DC magnetron sputtering system used to prepare TiN/ $\alpha-C$ nanocomposite coatings adhesion. Table I summarises the process conditions used for depositing the coatings.

X-ray diffraction (XRD) data of the films, in Bragg-Brentano $\theta-2 \theta$ geometry, were recorded in a Rigaku D/max 2200 Ultima X-ray powder diffractometer. The X-ray source was a $\mathrm{Cu} K_{\alpha}$ radiation $(\lambda=0.15418 \mathrm{~nm})$. Surface morphology of the coatings was investigated by scanning electron microscopy (Leo 440I). The corrosion products were characterised using energy dispersive X-ray analysis (EDX). Average surface roughness $\left(R_{\mathrm{a}}\right)$ of the coatings was measured by atomic force microscopy (AFM). The AFM (Surface Imaging Systems) was operated in the non-contact mode $^{23}$. The hardness measurements were performed in a nanoindenter (CSEM Instruments) at a load of $5 \mathrm{mN}$ using a Berkovich diamond indenter. At this load the indentation depth was much less than a tenth of the coating thickness, thus eliminating the effect of substrate on the hardness measurements. Ten indentations were made on each sample and results presented herein are averages of the ten measurements. Amorphous carbon coatings were also characterised using micro-Raman spectroscopy (Jobin - Yvon - Spex). The Raman spectrometer consisted of a microscope coupled confocally to a $300 \mathrm{~mm}$ focal length spectrograph equipped with two switchable gratings (300 and 1800 grooves $\mathrm{mm}^{-1}$ ). The excitation wavelength was $632.8 \mathrm{~nm}$ for Raman measurements. The spectrum was recorded in a Peltier cooled CCD detector. The data were collected with a $10 \mathrm{~s}$ data point acquisition time in the spectral range of $100-1200 \mathrm{~cm}^{-1}$. Further details about Raman set-up are reported in Ref. [24].

\section{Corrosion measurements}

Corrosion studies were made in $0.5 \mathrm{M} \mathrm{HCl}$ solution using a potentiodynamic polarisation unit consisting of three electrodes. One of the electrodes (area $=1 \mathrm{~cm}^{2}$ ) served as the working electrode and a platinum electrode, which was kept parallel to the working electrode, served as the counter electrode. A saturated calomel electrode (SCE) with a Luggin capillary acted as the reference electrode. This electrode was kept near the surface of the working electrode and measured the potential of the working 
electrode. The samples were coated with an epoxy resin, leaving only $1 \mathrm{~cm}^{2}$ area exposed. The samples were rinsed with de-ionised water before polarisation studies in the electrochemical cell; no other chemical treatments were given. The samples were immersed in the solution for about $0.5 \mathrm{~h}$ so that a steady state equilibrium potential, known as the open circuit potential (OCP), was attained. The polarisation of the samples was carried out, first in the cathodic direction and then anodically $( \pm 0.150 \mathrm{~V})$ from the OCP to include the Tafel region $( \pm 0.060$ to $\pm 0.120 \mathrm{~V})$ of the polarisation. The polarisation curves were recorded with a scan rate of $0.6 \mathrm{mV} \mathrm{s}^{-1}$ and Tafel plots obtained from the data. The corrosion current density $\left(j_{\text {corr }}\right)$ and corrosion potential relative to $\mathrm{SCE}\left(E_{\text {corr }}\right)$ were determined by extrapolating the straightline section of the anodic and cathodic Tafel lines.

For corrosion measurements two sets of coatings were deposited. In the first, the corrosion behaviour of $1.5 \mu \mathrm{m}$ thick TiN, $\alpha-\mathrm{C}$ and $\mathrm{TiN} / \alpha-\mathrm{C}$ nanocomposite coatings was studied. In the second, $100 \mathrm{~nm}$ thick nanocomposite coatings with varying TiN layer thicknesses $(0.6-2.8 \mathrm{~nm})$ were prepared and their corrosion behaviours compared with single layer $\mathrm{TiN}$ and $\alpha-\mathrm{C}$ coatings of similar thicknesses.

\section{RESULTS AND DISCUSSION}

\section{Structure of the coatings}

Figure 2 shows XRD data in the $2 \theta$ range of $10-70^{\circ}$ of a single layer $\alpha-\mathrm{C}$, a single layer $\mathrm{TiN}$ and a TiN $/ \alpha-\mathrm{C}$ nanocomposite coating deposited on tool steel substrate with a $\mathrm{Ti}$ interlayer. For the nanocomposite coating, the TiN layer thickness was $1.0 \mathrm{~nm}$ and the $\alpha-\mathrm{C}$ layer thickness was approximately $0.45 \mathrm{~nm}$. For the $\alpha-\mathrm{C}$ coating the strongest peak of graphite $\left(2 \theta=26^{\circ}\right)$ was absent in the diffraction pattern and no other reflections were observed, indicating the amorphous nature of the coating. Although, the graphite target was sputtered in an $\mathrm{Ar}+\mathrm{N}_{2}$ plasma the results reported herein do not show any evidence for the formation of a

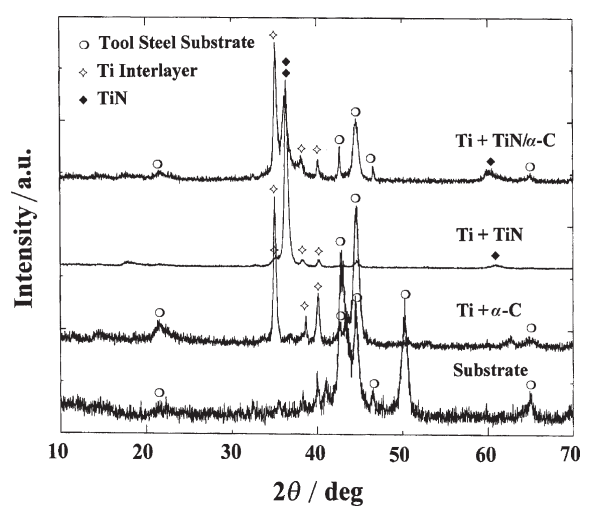

Figure 2. High-angle XRD data of a single layer $\alpha-C$, a single layer TiN and a TiN/ $\alpha-C$ nanocomposite coatings deposited on tool steel substrate. The Ti interlayer was used to improve adhesion of the coatings
$\mathrm{CN}_{\mathrm{x}}$ phase. This was confirmed by Raman spectroscopy. The Raman spectra of carbon coatings did not show evidence of any $\mathrm{C}-\mathrm{N}$ bonds and exhibited two broad peaks centred at $1354 \mathrm{~cm}^{-1}$ (D-band) and $1579 \mathrm{~cm}^{-1}$ (G-band), which are characteristic of an amorphous carbon phase ${ }^{25}$. The XRD data of the single layer TiN coating exhibited a sharp (111) reflection (FWHM $\left.=0.70^{\circ}\right)$, whereas the $\mathrm{TiN} / \alpha-\mathrm{C}$ coating exhibited a broad (111) reflection (FWHM $=1.02^{\circ}$ ), suggesting that incorporation of $\alpha-\mathrm{C}$ in the TiN matrix decreased the crystallite size of the nanocomposite coating. Absence of any higher angle reflections other than the (111) reflection in the XRD data suggested that TiN and TiN/ $\alpha-C$ nanocomposite coatings were $\{111\}$ textured.

\section{Hardness of the coatings}

While depositing nanocomposite coatings from the multilayer route, thicknesses of the individual layers (i.e. $\alpha-\mathrm{C}$ and TiN) play an important role in determining the mechanical properties of the coatings. Systematic studies on the variations of TiN and $\alpha-C$ layer thicknesses onto the mechanical properties of $\mathrm{TiN} / \alpha-\mathrm{C}$ nanocomposite coatings have been performed using a nanoindentation technique. In order to minimise the effect of surface roughness on the nanoindentation measurements, all the coatings were polished with $0.03 \mu \mathrm{m} \mathrm{Al}_{2} \mathrm{O}_{3}$ powder. In Figure 3, the variation of hardness of TiN $/ \alpha-\mathrm{C}$ nanocomposite coatings with TiN layer thickness is shown; variation of hardness with $\alpha$-C layer thickness will be reported later. In the present study, however, the $\alpha-\mathrm{C}$ layer thickness was fixed at approximately $0.45 \mathrm{~nm}$ and the TiN layer thickness was varied from 0.8 to $2.8 \mathrm{~nm}$. The thickness of $\alpha$-C layer was chosen at $0.45 \mathrm{~nm}$ because at this thickness the nanocomposite coatings exhibited the highest hardness. Single layer TiN and $\alpha$-C coatings deposited under similar deposition conditions showed hardnesses of 3300 and $800 \mathrm{~kg} \mathrm{~mm}^{-2}$, respectively. The hardness vs TiN layer thickness plot clearly indicated that the nanocomposite coatings exhibited a maximum hardness of $5100 \mathrm{~kg} \mathrm{~mm}^{-2}$ at a TiN layer thickness of

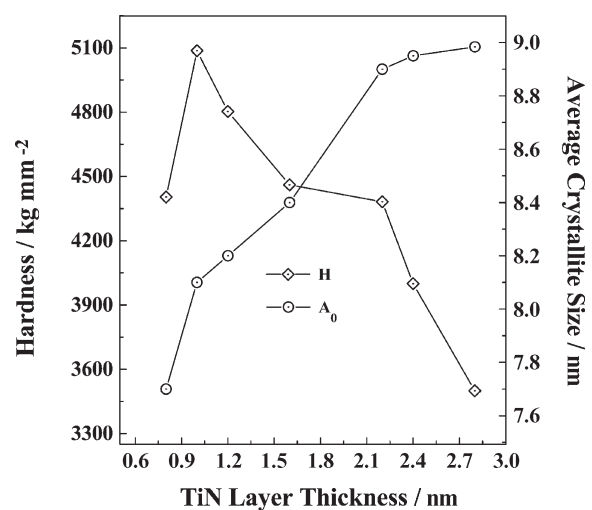

Figure 3. Variations of average crystallite size and nanoindentation hardness of TiN/ $\alpha-C$ nanocomposite coatings with TiN layer thickness. The $\alpha$-C layer thickness was approximately $0.45 \mathrm{~nm}$ and the total coating thickness was $1.5 \mu \mathrm{m}$
$1.0 \mathrm{~nm}$. At very small TiN layer thickness (i.e. $<1.0 \mathrm{~nm}$ ) the hardness decreased. The reason for this decrease is not very clear but it may presumably be due to a softening effect associated with inclusion of the soft $\alpha-\mathrm{C}$ phase in the hard TiN phase. At very high values of TiN layer thicknesses the hardness also decreased significantly. For example, coatings prepared with a TiN layer thickness of $2.8 \mathrm{~nm}$ showed a hardness of only $3400 \mathrm{~kg} \mathrm{~mm}^{-2}$. This decrease may be attributed to an increase in the crystallite size, as described later. Therefore, an optimum thickness of TiN and $\alpha$-C phases is required to achieve high hardness of the nanocomposite coatings.

The enhanced hardness of the nanocomposite coatings can be attributed to small crystallite size, which is described by the well-known Hall-Petch effect ${ }^{26}$. The average crystallite size $\left(\mathrm{nm}_{0}\right)$ of the nanocomposite coatings, as determined from the XRD data using the Scherrer formula ${ }^{27}$, was in between 7.7 and $9.0 \mathrm{~nm}$ and its variation with TiN layer thickness is shown in Figure 3. Clearly, the crystallite size decreased with a decrease in TiN layer thickness. Single layer TiN coatings, deposited under identical conditions, exhibited an average crystallite size of $12.0 \mathrm{~nm}$.

\section{Corrosion behaviour of the coatings}

\section{Corrosion of TiN/ $\alpha-C$ nanocomposite} coatings

Generally, PVD coatings are inert to chemical attack due to their high position in the electrochemical series. However, in practice galvanic and crevice corrosion between the coating and the substrate is exhibited because of the presence of defects such as micro-pores. The solution penetrates to the substrate via these defects. Where the porosity is very low, the behaviour exhibited is that of the coating. However, if the porosity is high, significant galvanic corrosion will occur between the substrate acting as the anode and the coating as the cathode. Hence, the corrosion current is a good indicator of the coating porosity. The potentiodynamic polarisation curves (Tafel plots) obtained for a tool steel substrate, a single layer $\mathrm{TiN}$ and a TiN/ $\alpha-\mathrm{C}$ nanocomposite coating in $0.5 \mathrm{M} \mathrm{HCl}$ solution are shown in Figure 4. The thickness of the coating was $1.5 \mu \mathrm{m}$ for all samples. For all coatings, a $0.5 \mu \mathrm{m}$ thick Ti interlayer was incorporated for improved adhesion. The corrosion current density and the corrosion potential ( $v s$ SCE) were determined by extrapolating the straight-line section of the cathodic and anodic Tafel lines, as shown in Figure 4. The data obtained from the Tafel plots are presented in Table II. After coating the substrate with $1.5 \mu \mathrm{m}$ thick TiN/ $\alpha$-C nanocomposite coating, $E_{\text {corr }}$ increased from -0.460 to $-0.310 \mathrm{~V}$, whereas, $j_{\text {corr }}$ decreased from 240 to $1.9 \mu \mathrm{A} \mathrm{cm}^{-2}$. This shift in the corrosion potential to a more positive value represents a more noble electrode potential being achieved, thus indicating improvement in the corrosion resistance of the tool steel substrate with 


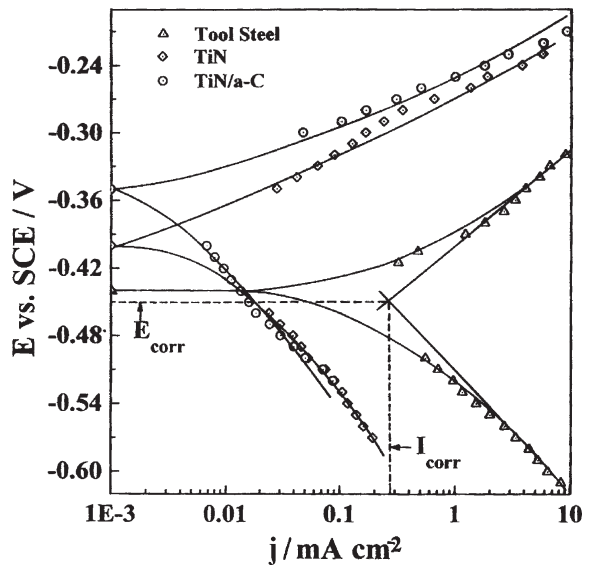

Figure 4. Potentiodynamic polarisation curves of a single layer TiN coating, a TiN/ $\alpha-C$ nanocomposite coating and a tool steel substrate in $0.5 \mathrm{M} \mathrm{HCl}$ solution. For the nanocomposite coating the TiN and $\alpha$-C layer thicknesses were 1.0 and approximately $0.45 \mathrm{~nm}$, respectively. The coating thickness was $1.5 \mu \mathrm{m}$

Table II. Corrosion characteristics of Ti interlayer, TiN, $\alpha-\mathrm{C}$, TiN/ $\alpha-\mathrm{C}$ nanocomposite coatings and tool steel substrate in $0.5 \mathrm{M} \mathrm{HCl}$ solution

\begin{tabular}{lcc}
\hline Sample & $\mathrm{E}_{\text {corr }}$ vs SCE / V & $\mathrm{j}_{\text {corr }} / \mu A \mathrm{~cm}^{-2}$ \\
\hline Steel & -0.460 & 240 \\
Ti/steel & -0.360 & 3.2 \\
TiN/steel & -0.375 & 2.1 \\
$\alpha-C / s t e e l$ & -0.385 & 11 \\
$($ TiN/ $\alpha$-C)/steel* & -0.310 & 1.9 \\
\hline
\end{tabular}

*TiN layer thickness $=1.6 \mathrm{~nm} ; \alpha$-C layer thickness $=0.45 \mathrm{~nm}$; total number of layers $=$ 1000 .

the nanocomposite coating. The corrosion current density is commonly utilised as an important parameter to evaluate the kinetics of corrosion reactions, the corrosion rate being normally proportional to the corrosion current density. The decrease in $j_{\text {corr }}$ of the coated substrate thus confirms the improvement in the corrosion resistance. Single layer TiN and $\alpha-\mathrm{C}$ coatings exhibited corrosion currents of 2.1 and $11.0 \mu \mathrm{A} \mathrm{cm}^{-2}$, and corrosion potentials of -0.375 and $-0.385 \mathrm{~V}$, respectively. The AFM imaging showed that before corrosion, the substrate exhibited very smooth surface morphology with an average surface roughness of $4.6 \mathrm{~nm}$. However, after corrosion the substrate became very rough and $R_{\mathrm{a}}$ increased to $266 \mathrm{~nm}$. The substrate coated with $\mathrm{TiN} / \alpha-\mathrm{C}$ nanocomposite coatings exhibited a roughness of $10 \mathrm{~nm}$ and did not change even after corrosion in $0.5 \mathrm{M} \mathrm{HCl}$ solution $(9.4 \mathrm{~nm}$ after corrosion), suggesting minimal chemical attack of the substrate and the coating. Similarly, $R_{\mathrm{a}}$ did not change significantly for TiN coated samples after corrosion. Furthermore, for TiN coatings little surface discoloration was observed after corrosion testing and no pits were observed confirming the good corrosion performance of the coatings.

The good corrosion resistance of even single layer TiN coatings was due to a dense microstructure with low through-coating porosity. Examination of samples under

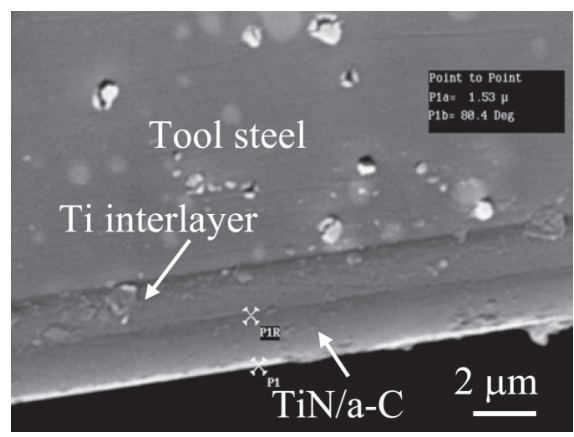

Figure 5. SEM cross-sectional micrograph of a typical TiN/ $\alpha$-C nanocomposite coating after corrosion in $0.5 \mathrm{M} \mathrm{HCl}$ solution, showing no corrosion attack of the coating

SEM showed that both TiN and nanocomposite coatings exhibited very smooth surface morphology, whereas, $\alpha-\mathrm{C}$ showed a slightly granular surface morphology. This may explain why this sample exhibited a higher corrosion current. After corrosion in $0.5 \mathrm{M} \mathrm{HCl}$, the SEM micrographs in planar view showed no evident corrosion of the $\mathrm{TiN}$ and $\mathrm{TiN} / \alpha-\mathrm{C}$ nanocomposite coatings. A typical cross-sectional SEM image of a TiN $/ \alpha-C$ nanocomposite coating after corrosion in $0.5 \mathrm{M} \mathrm{HCl}$ solution, Figure 5, shows a non-columnar microstructure with no microcracks present. The dense microstructure of the coatings can be attributed to ion bombardment during deposition, lower growth rates $\left(0.2 \mathrm{~nm} \mathrm{~s}^{-1}\right)$, moderately high deposition temperature $\left(300^{\circ} \mathrm{C}\right)$ and very small layer thicknesses. These parameters resulted in a fine grained morphology of the coatings. Furthermore, in all these coatings a $0.5 \mu \mathrm{m}$ thick Ti interlayer was incorporated to improve adhesion the presence of this Ti interlayer may also have contributed to the fine structure of the nitride coatings. Massiani et al. ${ }^{28}$ have reported that $(\mathrm{Ti}+\mathrm{TiN})$ deposited on iron exhibited a more homogeneous and compact microstructure than TiN deposited on the same substrate.

\section{Corrosion of $\mathrm{Ti}$ interlayer}

As all the coatings contained a $0.5 \mu \mathrm{m}$ thick $\mathrm{Ti}$ interlayer, on tool steel the corrosion behaviour of this deposited $\mathrm{Ti}$ interlayer was studied independently. XRD data (a)

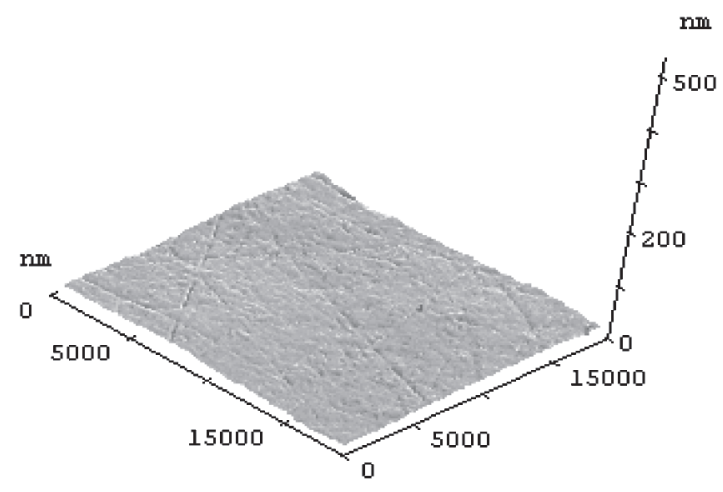

\section{Substrate}

(b)

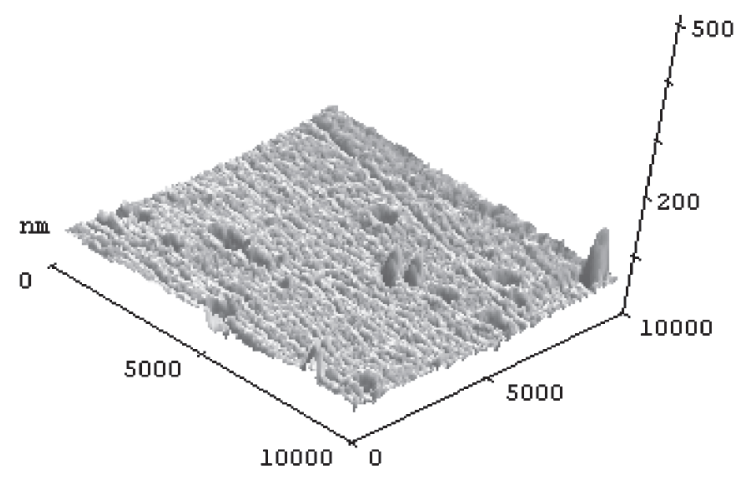

TiN

(c)

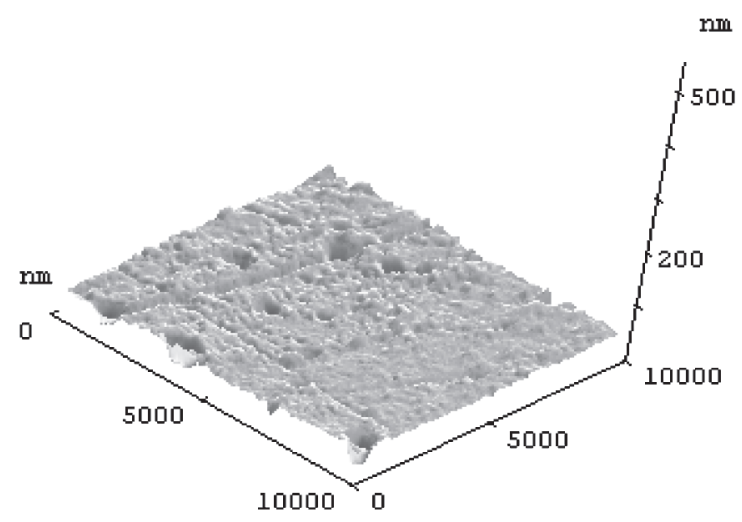

\section{$\mathrm{TiN} / \alpha-\mathrm{C}$}

Figure 6. Three-dimensional AFM images of: (a) tool steel substrate (b) $100.0 \mathrm{~nm}$ thick TiN coating and (c) $100.0 \mathrm{~nm}$ thick TiN/ $\alpha$-C nanocomposite coating before corrosion 
showed that the interlayer was polycrystalline with an average crystallite size of $10 \mathrm{~nm}$. In $0.5 \mathrm{M} \mathrm{HCl}$ solution, a $0.5 \mu \mathrm{m}$ thick $\mathrm{Ti}$ interlayer on tool steel exhibited $j_{\text {corr }}$ of $3.2 \mu \mathrm{A} \mathrm{cm}^{-2}$ and $E_{\text {corr }}$ of $-0.360 \mathrm{~V}$. These results demonstrate the good protective nature of Ti as a coating. The passive behaviour of the Ti interlayer is believed to be due to formation of a very thin oxygen rich $\mathrm{Ti}$ layer with high resistance to localised attacks. This assumption was supported by EDX analysis of the Ti coating before and after corrosion, which showed that oxygen increased from 1.8 to $4.5 \mathrm{wt}-\%$. The higher polarisation resistance of $\mathrm{Ti}$ coating alone, as compared to TiN and $\mathrm{Ti}+\mathrm{TiN}$, has also been observed by Massiani et al. ${ }^{28}$ and has been attributed to the formation of oxidised titanium, as confirmed by SIMS analysis.

\section{Effect of TiN layer thickness}

The results presented above suggest that the nanocomposite coatings exhibited improved corrosion protection of the substrate compared to the single layer TiN coatings, though this improvement was not very large. To further substantiate the improved corrosion properties of nanocomposite coatings, $100.0 \mathrm{~nm}$ thick single layer $\mathrm{TiN}$, single layer $\alpha-\mathrm{C}$ and $\mathrm{TiN} / \alpha-\mathrm{C}$ nanocomposite coatings were deposited on tool steel substrates. To ensure that only the inherent corrosion properties of the coatings were investigated, all the coatings were deposited directly on tool steel substrates without a $\mathrm{Ti}$ interlayer. However, to improve the adhesion, substrates were in situ cleaned in Ar plasma for $15 \mathrm{~min}$, as described earlier. Furthermore, for the nanocomposite coatings the $\alpha-\mathrm{C}$ layer thickness was approximately $4.5 \mathrm{~nm}$ and the TiN layer thickness was varied from 0.6 to $2.8 \mathrm{~nm}$. Lower coating thicknesses were chosen as at lower thicknesses a large number of micropores/pinholes are expected to be present, which lead to higher corrosion current. For example, a strong increase of pore density of PVD TiN coatings with decreasing coating thickness has been reported in the literature ${ }^{2,29}$. Figure 6 shows typical AFM images of tool steel substrate, a TiN (100.0 nm thick) and a $\mathrm{TiN} / \alpha-\mathrm{C}$ nanocomposite $(100.0 \mathrm{~nm}$ thick) coatings. The polished substrate exhibited a $R_{\mathrm{a}}$ of $5.2 \mathrm{~nm}$, however, the TiN coating roughness was $8.7 \mathrm{~nm}$. For nanocomposite coatings, $R_{\mathrm{a}}$ decreased from 7.35 to $6.26 \mathrm{~nm}$ as the TiN layer thickness decreased from 2.8 to $0.6 \mathrm{~nm}$. Variation of $j_{\text {corr }}$ with TiN layer thickness is shown in Figure 7. Single layer $\mathrm{TiN}$ and $\alpha-\mathrm{C}$ coatings of similar thicknesses exhibited corrosion currents of 6.5 and $13.0 \mu \mathrm{A} \mathrm{cm}^{-2}$, respectively. The nanocomposite coatings prepared at $\mathrm{TiN}$ and $\alpha-\mathrm{C}$ layer thicknesses of 0.8 and $0.45 \mathrm{~nm}$, respectively showed a $j_{\text {corr }}$ value of $2.2 \mu \mathrm{A} \mathrm{cm}^{-2}$, which was about one third that of the value exhibited by TiN coating of similar thickness. The slope of the curve demonstrated that the corrosion current decreased with a decrease in TiN layer thickness. This was further confirmed by

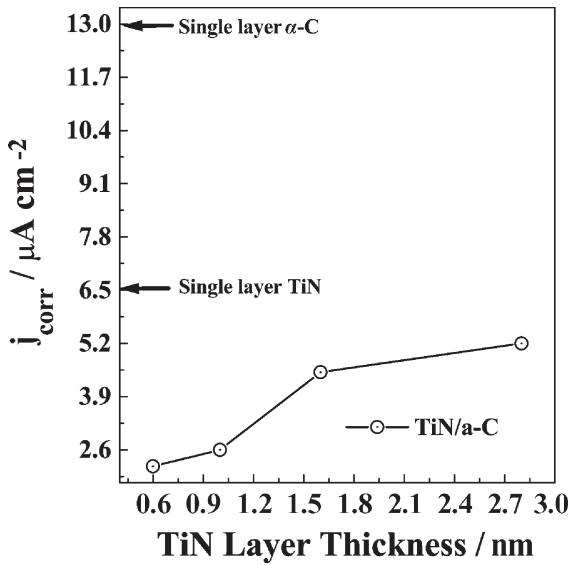

Figure 7. Variation of $j_{\text {corr }}$ with TiN coating thickness for TiN/ $\alpha$-C nanocomposite coatings deposited on tool steel substrate. The $\alpha$-C laver thickness was approximately $0.45 \AA$ and total coating thickness was $100.0 \AA$ A Also shown are $j_{\text {cor }}$ values for single layer TiN and $\alpha$-C coatings deposited under similar conditions

examining these samples under SEM. Unlike the $1.5 \mu \mathrm{m}$ thick coatings, the corrosion products could be seen visually on the thin coating. Figure 8 shows SEM micrographs of a $100.0 \mathrm{~nm}$ thick TiN coating and nanocomposite coatings deposited at various TiN layer thicknesses after corrosion. The white dots seen in the micrographs represented the corrosion pits along the micropores. This was confirmed by EDX analysis of these pits. Clearly the size and the density of the corrosion pits decreased with a decrease in TiN layer thickness.

\section{CONCLUSIONS}

TiN/ $\alpha$-C nanocomposite coatings exhibited a maximum hardness of $5100 \mathrm{~kg} \mathrm{~mm}^{-2}$ as compared to $3300 \mathrm{~kg} \mathrm{~mm}^{-2}$ for single layer TiN coatings deposited under similar conditions. The enhancement in the mechanical properties of the nanocomposite coating is attributed to small crystallite size. The XRD data showed that for an $\alpha$-C layer thickness of approximately $0.45 \mathrm{~nm}$ the average crystallite size of TiN/ $\alpha-\mathrm{C}$ nanocomposite coatings decreased with a decrease in TiN layer thickness and the coatings showed a maximum hardness for an average crystallite size of $8.0 \mathrm{~nm}$. A $1.5 \mu \mathrm{m}$ thick $\mathrm{TiN} / \alpha-\mathrm{C}$ nanocomposite coating showed a corrosion current of $1.9 \mu \mathrm{A} \mathrm{cm}^{-2}\left(E_{\text {corr }}=-0.310 \mathrm{~V}\right)$ as compared to $240 \mu \mathrm{A} \mathrm{cm}^{-2}\left(E_{\text {corr }}=-0.460 \mathrm{~V}\right)$ for a tool steel substrate in $0.5 \mathrm{M} \mathrm{HCl}$ solution. The nanocomposite coatings exhibited improved corrosion protection of the tool steel substrate as compared to the single layer TiN coatings. Enhancement in the corrosion resistance of the nanocomposite coatings is attributed to small crystallite size, reduced micro-porosity and dense

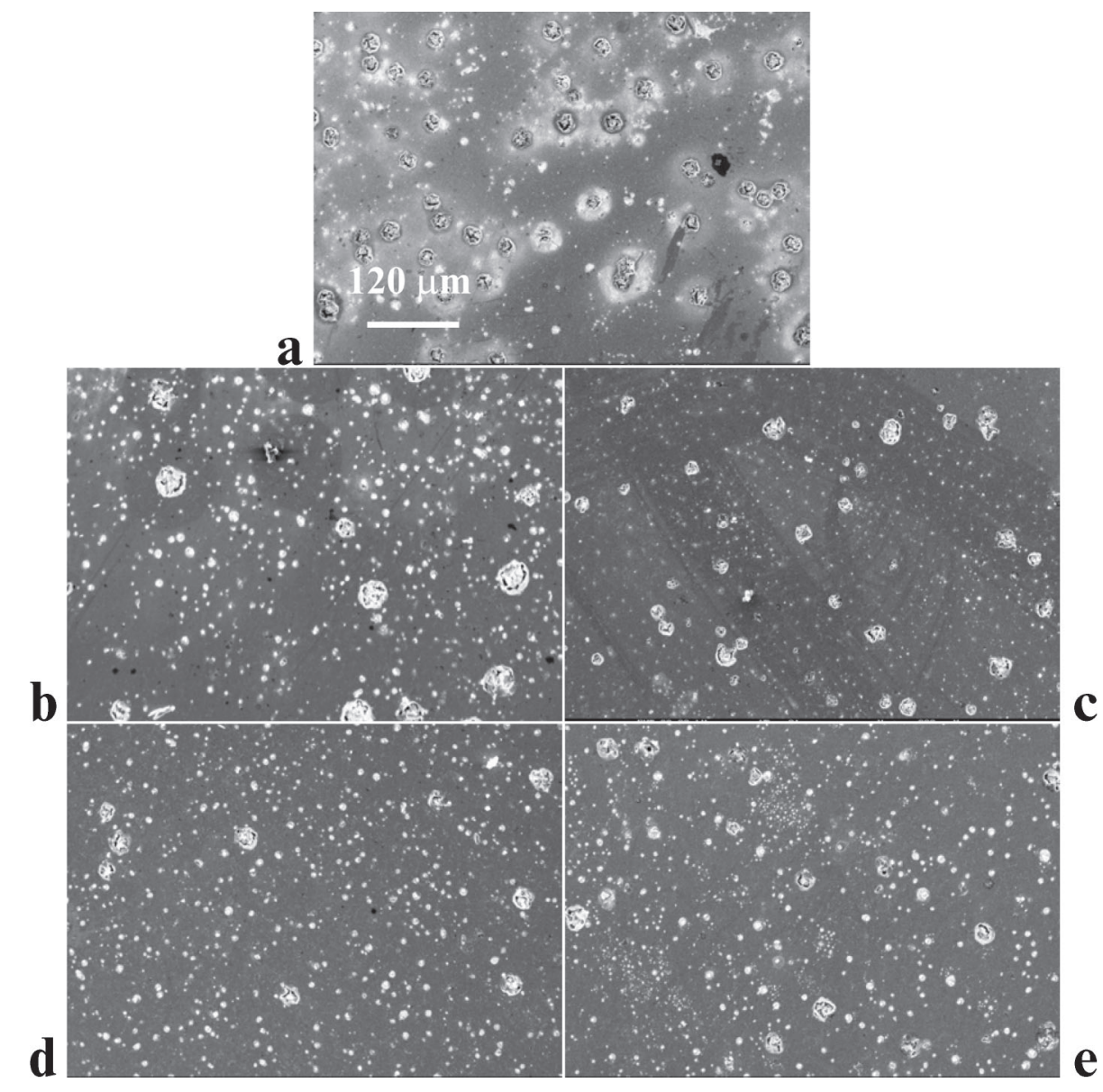

Figure 8. SEM micrographs of: (a) single layer TiN coating and (b-e) TiN/ $\alpha$-C nanocomposite coatings deposited on tool steel substrates after corrosion in $0.5 \mathrm{M} \mathrm{HCl}$ solution. The total coating thickness was $100.0 \mathrm{~nm}$. For the nanocomposite coatings the $\alpha$-C layer thickness was approximately $0.45 \mathrm{~nm}$ and the TiN layer thickness was (b) $2.8 \mathrm{~nm}$, (c) $1.6 \mathrm{~nm}$, (d) $1.0 \mathrm{~nm}$ and (e) $0.6 \mathrm{~nm}$ 
microstructure. Potentiodynamic polarisation studies conducted on $100.0 \mathrm{~nm}$ thick nanocomposite coatings revealed that for a given $\alpha-C$ layer thickness (i.e. approximately $0.45 \mathrm{~nm}$ ) the corrosion current decreased with a decrease in TiN layer thickness $(2.8-0.6 \mathrm{~nm})$. Furthermore, $100.0 \mathrm{~nm}$ thick $\mathrm{TiN} / \alpha-\mathrm{C}$ nanocomposite coating improved the corrosion protection of the tool steel substrate by a factor of three as compared to TiN coating of similar thickness. These results were supported by SEM studies. The SEM micrographs of the corroded samples showed that the density and diameter of the corrosion pits were small for nanocomposite coatings as compared to single layer TiN coatings of similar thicknesses.

\section{ACKNOWLEDGEMENTS}

The authors would like to thank Ms. Kalavati and Mr. M. A. Venkataswamy for recording SEM data. Dr. Anjana Jain is thanked for recording XRD data. The authors thank the Director, NAL for giving permission to publish these results. This work was supported by the Department of Science and Technology, New Delhi and the Council of Scientific and Industrial Research, New Delhi, India.

\section{REFERENCES}

1. U. Helmersson, J.-E. Sundgren and J. E. Greene: J. Vac. Sci. Technol. A., 1986, 4, 500 .
2. H. A. Jehn: Surf. Coat. Technol., 2000, 125, 212.

3. I. Petrov, L. Hultman, U. Helmersson, J.-E. Sundgren and J.E. Greene: Thin Solid Films, 1989, 169, 299.

4. C. Liu, Q. Bi and A. Matthews: Corrosion Sci., 2001, 43, 1953.

5. C. Liu, A. Leyland, S. Lyon and A. Matthews: Surf. Coat. Technol., 1995, 76-77, 615.

6. P. Engel, G. Schwarz and G. K. Wolf: Surf. Coat. Technol., 1998, 98, 1002.

7. G. Bertrand, H. Mahdjoub and C. Meunier: Surf. Coat. Technol., 2000, 126, 199.

8. F. Lang and Z. Yu: Surf. Coat. Technol., 2001, 145, 80.

9. Y. Massiani, A. Medjahed, J. P Crousier, P. Gravier and I. Rebatel: Surf. Coat. Technol., 1991, 45, 115.

10. J. Creus, H. Idrissi, H. Mazille, F. Sanchette and P. Jacquot: Surf. Coat. Technol., 1998, 107, 183

11. F. Vacandio, Y. Massiani, M. Eyraud, S. Rossi and L. Fedrizzi: Surf. Coat. Technol., 2001, 137, 284.

12. L. Cunha, M. Andritschky, L. Rebouta and K. Pischow: Surf. Coat. Technol., 1999, 116-119, 1152.

13. Y. Massiani, P. Gravier, L. Fedrizzi and F. Marchetti: Thin Solid Films, 1995, 261, 202.

14. T. Sugama: Mater. Lett., 1999, 38, 227.

15. M. Fenker, M. Balzer, H. A. Jehn, H. Kappl, J. J. Lee, K. H. Lee and H. S. Park: Surf. Coat. Technol., 2002, 150, 101.
16. M. Nordin, M. Herranen and S. Hogmark, Thin Solid Films, 1999, 348 , 202.

17. C. Liu, A. Leyland, Q. Bi and A. Matthews: Surf. Coat. Technol., 2001, 141, 164.

18. S. Veprek, P. Nesladek, A. Niederhofer, F. Glatz, M. Jilek and M. Sima: Surf. Coat. Technol., 1998, 108-109, 138.

19. P. Holubar, M. Jilek and M. Sima: Surf. Coat. Technol., 2000, 133-134, 145.

20. S. Zhang, D. Sun, Y. Fu and H. Du: Surf. Coat. Technol., 2003, 167, 113.

21 S. Veprek and S. Reiprich: Thin Solid Films, 1995, 268, 64.

22. J. Li, Y. Sun, X. Sun and J. Qiao: Surf. Coat. Technol. (in press).

23. H. C. Barshilia and K. S. Rajam: Surf. Coat. Technol., 2002, 155, 195

24. H. C. Barshilia and K. S. Rajam: $J$. Mater. Res. (in press).

25. D. Papadimitriou, G. Roupakas, C. Xue, A. Topalidou, Y. Panayiotatos, C. A. Dimitriadis and S. Logothetidis: Thin Solid Films, 2002, 414, 18.

26. A. Lasalmonie and J.L. Strudel: $J$. Mater. Sci., 1986, 21, 1837.

27. L. V. Azaroff: 'Elements of X-ray crystallography', 552; 1968, New York, McGraw-Hill

28. Y. Massiani, J. Crousier, L. Fedrizzi, A. Cavalleri and P. L. Bonora: Surf. Coat. Technol., 1987, 33, 309.

29. H. Uchida, S. Inoue and K. Koterazawa: Mater. Sci. Eng. A, 1997, 234-236, 649. 


\section{AUTHOR QUERY}

Author name: Barshilia et al.

Paper no.: TIMF 489

Init. issue: 82(4)

$\begin{array}{ll}\text { Query no. } & \text { Query } \\ 1 & \text { Are the units used correct here? } \\ 2 & \text { Please supply page ranges for all journal references. } \\ 3 & \text { Please supply updated information if available. } \\ 4 & \text { Please supply updated information if available. }\end{array}$

